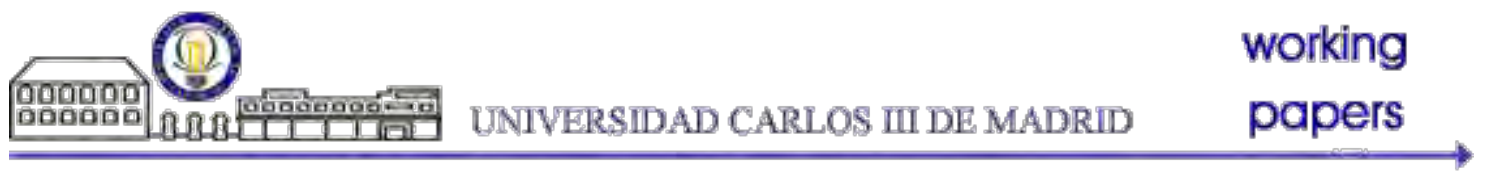

Working Paper 11-20

Statistics and Econometrics Series 15

Departamento de Estadística

July 2011

Universidad Carlos III de Madrid

Calle Madrid, 126

28903 Getafe (Spain)

Fax (34) 91 624-98-49

\title{
IMPROVING QUALITY ASSESSMENT OF COMPOSITE INDICATORS IN UNIVERSITY RANKINGS: A CASE STUDY OF FRENCH AND GERMAN UNIVERSITIES OF EXCELLENCE
}

\author{
Mónica Benito and Rosario Romera*
}

\begin{abstract}
Composite indicators play an essential role for benchmarking higher education institutions. One of the main sources of uncertainty building composite indicators and, undoubtedly, the most debated problem in building composite indicators is the weighting schemes (assigning weights to the simple indicators or subindicators) together with the aggregation schemes (final composite indicator formula). Except the ideal situation where weights are provided by the theory, there clearly is a need for improving quality assessment of the final rank linked with a fixed vector of weights.

We propose to use simulation techniques to generate random perturbations around any initial vector of weights to obtain robust and reliable ranks allowing to rank universities in a range bracket. The proposed methodology is general enough to be applied no matter the weighting scheme used for the composite indicator. The immediate benefit achieved is a reduction of the uncertainty associated with the assessment of a specific rank which is not representative of the real performance of the university, and an improvement of the quality assessment of composite indicators used to rank. To illustrate the proposed methodology we rank the French and the German universities involved in their respective 2008 Excellence Initiatives.
\end{abstract}

Key words: Composite indicators. Rankings. Benchmarking. Higher Education Institutions. Weighting schemes. Simulation techniques.

* Department of Statistics, Universidad Carlos III de Madrid, C/ Madrid 126, 28903

Getafe (Madrid), e-mail: monica.benito@uc3m.es and rosario.romera@uc3m.es . 


\title{
Improving quality assessment of composite indicators in university rankings: a case study of French and German universities of excellence
}

\author{
M. Benito and R. Romera \\ Department of Statistics \\ Universidad Carlos III de Madrid
}

\begin{abstract}
Composite indicators play an essential role for benchmarking higher education institutions. One of the main sources of uncertainty building composite indicators and, undoubtedly, the most debated problem in building composite indicators is the weighting schemes (assigning weights to the simple indicators or subindicators) together with the aggregation schemes (final composite indicator formula). Except the ideal situation where weights are provided by the theory, there clearly is a need for improving quality assessment of the final rank linked with a fixed vector of weights.

We propose to use simulation techniques to generate random perturbations around any initial vector of weights to obtain robust and reliable ranks allowing to rank universities in a range bracket. The proposed methodology is general enough to be applied no matter the weighting scheme used for the composite indicator. The immediate benefit achieved is a reduction of the uncertainty associated with the assessment of a specific rank which is not representative of the real performance of the university, and an improvement of the quality assessment of composite indicators used to rank. To illustrate the proposed methodology we rank the French and the German universities involved in their respective 2008 Excellence Initiatives.

Key words: Composite indicators. Rankings. Benchmarking. Higher Education Institutions. Weighting schemes. Simulation techniques.
\end{abstract}

\section{Introduction}

Composite indicators (or indices) are of increasing interest for benchmarking institutions's performance. Organizations such as the United Nations, the European Commission and others have developed and used composite indicators in order to provide rankings of institutions or countries. Among the different instruments of quality assessment in higher education, rankings probably get the most public attention.

There clearly is a demand for ranking in the field of higher education, but there are also questions about the quality, impact and eventual validity of the outputs and the conclusions. It is claimed that rankings have several purposes: to respond to demands from consumers for easily interpretable information on the standing of higher education institutions, to stimulate competition among institutions, to better understand the different types of institutions and programs, to serve as part of a framework for national assessment, accountability and quality assurance in the higher education system and, finally, linked to a national framework for quality, rankings serve to generate a debate that contributes to the definition of 'quality' of higher education, complementing the rigorous work conducted in the context of quality assessment and review performed by public and independent accrediting agencies. 
On the other hand, critiques of rankings (in the form of league tables) come from a number of sources and are based on methodological, pragmatic, or even moral and philosophical concerns. The main criticisms focus on the validity of the selection of subindicators, dealing with missing values, normalization methods, weighting of indicators, reliability/robustness in league positions or composite indicators formula's changes (Harvey 2008). In response to the legitimate concerns about the quality of Higher Education Institutions rankings, in May 2006, the International Ranking Expert Group (IREG) developed and endorsed a guideline document - the Berlin Principles on Ranking of Higher Education Institutions (Berlin Principles in short), consisting of sixteen descriptive and prescriptive principles for ranking covering four aspects: the purpose and goal of ranking; the design and weighting of indicators; the collection and processing of data; and the presentation of ranking results (CHE/CEPES/IHEP (2006)). Chen and Liu (2008) propose concrete 'Fourteen Criteria' which, if followed, they claim could enhance the quality of ranking.

As Sadlak, Merisotis and Liu (2008) pointed out, although a positive view of rankings is not unanimously shared, it is likely that the naysayers are fighting a losing battle. The number of meetings and references to ranking of higher education confirms a wide interest and attention to this phenomenon.

There is no single concept or model of ranking. Rankings vary in their aims and target groups as well as in terms of what they measure, how they measure it and how they implicitly define quality

(see for instance Pike 2004; Dill and Soo 2005; Usher and Savino 2007; Bastedo and Bowman 2010). Furthermore, Stolz et al. (2010) provide a Ranking of rankings, a recent study benchmarking twenty-five higher education ranking systems in Europe, and Aguillo et al. (2010) present an interesting comparison of rankings of world universities by using a set of similarity measures.

There are different approaches among papers on university rankings: the largest category is composed by papers that reflect on international or national rankings and the smallest category consists of papers that contribute to the improvement of the methodologies of construction of the rankings. The present paper belongs to the latter group.

University rankings are very appealing, in that provide a single score that allows, at a glance, to situate institutions in the worldwide context or in their national context. However, this simplicity of use can be highly misleading in that most rankings are based on a simple formula that aggregate subjectively, most of the times, chosen indicators. Saisana and D'Hombres (2008) present a thorough uncertainty and sensitivity analysis of the 2007 'Shanghai Jiao Tong University Academy Ranking of World Universities' (STJU) and the 2007 Times Higher Education Supplement (THES) ranking for the Top100 and Top200 universities, respectively. Findings and recommendations put forward by that report reveal that the rank of more than half of the institutions is highly sensitive to the methodological assumptions and the choice of indicators, consequently, robustness analysis is highly recommended and for that purpose they propose a multi modeling approach based on crossvalidation principles. In a recent study, Geraci and Degli (2011) compare several rankings used to evaluate the prestige and merit of Italian universities and consider alternative approaches to academic rankings.

We believe that while standard university rankings may not be informative about the real position of most of the institutions, a robust analysis applied to composite indicators allows ranking universities in a range bracket providing more accurate information. The immediate benefit achieved is a reduction of the uncertainty associated with the assessment of a specific rank which is not representative of the real performance of the university, and an improvement of the quality assessment of composite indicators used to rank. Although we share a coincident viewpoint as in Saisana, Saltelli and Tarantola (2005), our methodology is 
different in what we do not follow a sensitivity analysis approach and we focus on robustness itself.

One of the main sources of uncertainty building composite indicators and, undoubtedly, the most debated problem in building composite indicators is the weighting schemes (assigning weights to the simple indicators or subindicators) together with the aggregation schemes (final composite indicator formula). The difficulty lies in assessing properly the different perspectives about the relevance of the simple indicators. The methodology proposed in the present paper can help in any aggregation step of benchmarking exercises: simple indicators or even composite indicators.

Ideally the weighting of indicators should be underpinned by theory but in practice it seems that indicators are assigned weights not always in a rationale manner. Nevertheless, a number of weighting techniques exits. Some of them are derived from statistical models (factor analysis, data envelopment analysis and unobserved components models) and others are derived from participatory methods (expert surveys, analytic hierarchy processes, conjoint analysis). Ding and Qiu (2011) describes an approach to improve the indicator weights integrating the subjective and objective weights to reflect both the subjective considerations of experts and the objective information obtained by mathematical methods. A different viewpoint follows the multidimensional Center for Higher Education Development (CHE)' ranking. Three central methodological principles of the CHE ranking distinguish it from many other ranking approaches (Federkail 2008). First, the main target group of the ranking is school leavers seeking to became university entrants. Thus, according to specific subject or program, the ranking does not rank whole universities, but only single subjects. Second, and in our perspective its most innovative feature, the CHE ranking does not calculate an overall composite indicator. Instead, it proposes a 'self-service' approach by providing a multidimensional ranking in which each indicator is presented separately. Decisions about the relevance (or 'weights') of subindicators are left to the user. Third, instead of league tables, the CHE-rank orders universities in three groups: according to the upper and the lowest quartiles, the best universities are clustered into the top group; the worst into the bottom group; and the rest constitute an intermediate middle group.

Whatever the criteria adopted to fix the weights except the ideal situation where weights are provided by the theory, there is the need of searching for stability and robustness of the final rank linked with that fixed vector of weights. How the ranked institutions react under small changes in the relative importance of the simple indicators given by the weights values?.

The main findings of the paper are: (1) to develop a general methodology in building robust rankings based on simulation techniques and (2) to apply these results in benchmarking some European universities included in Excellence Initiatives.

The rest of the paper is organized as follows. Section 2 presents the methodological aspects in obtaining robust ranks by building perturbations of the weights of the composite indicators. Section 3 illustrates the proposed methodology providing robust ranks for a casestudy: the 2008 excellence French and German universities and compare these results with the ones obtained by using the weighting scheme proposed by Ding and Qiu (2011). Section 4 summarizes our conclusions and extensions.

\section{Methodological aspects in building robust ranks}

General sources of uncertainty in building composite indicators arise from at least one of the following steps in constructing composite indicators: selection of simple indicators, data selection, data normalization, weighting scheme and weights' vector, and aggregating 
composite indicators (final composite indicator formula). We focus on the last two issues and we develop a robust methodology general enough for linear weighting or aggregating schemes.

\subsection{The robustness principles}

To assess robustness in some mechanism is generally understood as "to present the quality of being able to withstand stresses, pressures, or changes in procedure or circumstance. A system, organism or design may be said to be "robust" if it is capable of coping well with variations (sometimes unpredictable variations) in its operating environment with minimal damage, alteration or loss of functionality". From the statistical point of view, a robust procedure is such that produce estimators that are not unduly affected by small departures from model assumptions. In the higher education rankings's context what we desire to achieve is that small variations in the production of the rank have little effect in the ranked group of institutions.

In what follows we focus on linear weighting schemes for which we develop the robustness principles. Note that they equally hold for aggregating composite indicators schemes. It should be emphasized when using a linear additive aggregation technique, a necessary condition for the existence of a proper composite indicator is to achieve mutually independence between simple indicators (at least mutually preferentially independence in the sense of Debreu (1960)).

A composite indicator $\mathrm{CI}_{\mathrm{i}}$ for a given institution $i$ is most often a simple linear weighted function of a total of $p$ simple normalized indicators $\mathrm{I}_{11}, \ldots, \mathrm{I}_{\mathrm{ip}}$ with weights $\mathrm{w}_{1}, \ldots, \mathrm{W}_{\mathrm{p}}$

$$
C I_{i}=\sum_{j=1}^{p} I_{i j} w_{j}
$$

Let $\mathrm{x}_{\mathrm{ij}}$ be the raw value of the simple indicator $\mathrm{X}_{\mathrm{j}}$ for country $i$. It is a standard practice to normalize the data taking into account their properties with respect to the measurement units in which the simple indicators are expressed. The most frequent normalization procedures used in the literature for data normalization are (i) reescaling or (ii) standardizing. Thus, the $p$ normalized simple indicators are given by

$$
\begin{aligned}
& \text { (i) } I_{i j}=\frac{x_{i j}}{\max _{i}\left\{x_{i j}\right\}}, \text { or } I_{i j}=\frac{x_{i j}-\min _{i}\left\{x_{i j}\right\}}{\operatorname{range}\left\{X_{j}\right\}} \\
& \text { (ii) } I_{i j}=\frac{x_{i j}-\operatorname{median}\left\{X_{j}\right\}}{\operatorname{std}\left\{X_{j}\right\}}
\end{aligned}
$$

respectively. The group of institutions is then ranked according to the $\mathrm{CI}_{\mathrm{i}}$ values (1).

From the methodological point of view we observe that the vector of the relative weights of the simple indicators $\left(\mathrm{w}_{1}, \ldots, \mathrm{w}_{\mathrm{p}}\right)$ is composed by non-negative values $\mathrm{w}_{\mathrm{j}}$ such that

$$
\sum_{j=1}^{p} w_{j}=1
$$

Note that these values are individually used to assess the relative importance of each simple indicator $X_{j}$ into the convex linear combination (1). We propose to consider small 
perturbations for each $\mathrm{w}_{\mathrm{j}}$ by adding or subtracting small random quantities ranging in $(0, \mathrm{~s})$ where $\mathrm{s}$ is arbitrarily chosen according to the restrictions $0<\mathrm{s}<\mathrm{w}_{\mathrm{j}}$ for all $j$, and such (2) is guaranteed. Technically, for each $\mathrm{w}_{\mathrm{j}}$ we generate a number of uniform values over the interval $\left(\mathrm{w}_{\mathrm{j}}-\mathrm{S}, \mathrm{w}_{\mathrm{j}}+\mathrm{s}\right)$ and for each vector of weights satisfying (2) we evaluate the corresponding $\mathrm{CI}_{\mathrm{i}}$ values. Then, the institutions are ranked according to these values.

Let assume that after the simulations we obtain $m$ vectors of distorted weights such that (2) holds. It means that each institution has $m$ rankings. Our suggestion is to generate the resulting ranking in a robust manner. Thus, for each institution instead of the averaged ranking we consider the Median and the range (5th-quantile, 95th-quantile) of the distribution of its $m$ rankings. Note that the information provided by the range (5th-quantile, 95thquantile) regards the expected ranked positions achieved by the institutions excluding the lower 5 percent and the higher 5 percent of them. The simulations are carried out according to a general Monte Carlo scheme (see Algorithm 1 in Appendix 1). From the geometrical point of view considers the distorted vectors of weights as points randomly generated in $\mathfrak{R}^{\mathrm{n}}$ such that they live in the intersection of the n-dimensional hipercube and the n-1-simplex in $\mathfrak{R}^{\mathrm{n}}$. Different schemes of perturbation can be considered under this methodology. Note that different patterns of variability of the weights generate different geometric areas to be considered in the Monte Carlo simulations. According to a situation reflecting a more restrictive variability range of the perturbations, we propose for example, to consider as random perturbations of the initial vector of weights $\mathrm{w}^{(0)}$, the vectors living in the hipersurface obtained as the intersection of the sphere centered at the point $\mathrm{w}^{(0)}$ and radius $S$ and the $n$-1-simplex in $\mathfrak{R}^{\mathrm{n}}$. This algorithm is based on the methodology of Cook (1957) and Marsaglia (1972) (see Algorithm 2 in Appendix 1). Complementary to the algorithms proposed, it would be informative to include additional restrictions in any dimension. For instance, if in consultation with higher education experts it is clear that some simple indicator has to be higher than a fixed threshold, the algorithm would include an additional restriction over that weight. Or that we are interested in assuming that the weight of the second simple indicator has to be twice the first. This is equivalent to include the restriction $\mathrm{w}_{2}=2 \mathrm{w}_{1}$ in Algorithm 2, that is, the plane $\mathrm{w}_{2}-2 \mathrm{w}_{1}=0$, which generates a new geometric area.

This idea of random simulation we propose is the centerpiece to mitigate potential bias in weights' selection and offers a simple way to rank institutions in a robust manner according to a plurality of possible scenarios. In addition, we propose to consider for each institution the $5 t h, 50 t h$ and 95th quantiles of the distribution of its $m$ generated rankings as explained above.

With the proposed methodology there are some interesting improvements in comparison to the work proposed by Ding and Qiu (2011): (1) the integration to the subjective weights and the objective weights using the additive and multiplicative mathematical model, respectively, is highly influenced by the subjective judgment, whereas with the random simulation we propose about the initial vector of weights (subjective weights) we obtain a plurality of objective possible scenes, (2) Ding and Qiu choose the better between the different weights by using the sum of the absolute difference in rank between the university rankings in 5 years with each kind of weights just to minimize the fluctuations of the university rankings. Nevertheless, with this idea there is an important loss of information since it is not known how the ranked universities react under small changes in the weights values and (3) the integrative weights computed by Ding and Qiu can indeed be included in the resulting random simulation we propose. 


\section{An application to the French and German universities of excellence}

Since 2007 the Excellence Initiative in Germany aims to promote top-level research and to improve the quality of German universities and research institutions. The competition was run by the German Research Foundation (DFG) (Deutsche Forschungsgemeinschaft) and the German Council of Science and Humanities in three lines: (i) Graduate Schools to promote young scientists and researchers, (ii) Clusters of Excellence to promote cuttingedge research and (iii) Institutional Strategies on projects to promote top-level research. A total of 1.9 billion Euros was made available by the Federal and State Governments to fund the selected projects for the three funding lines of the initiative. This unique competition has already had a sustained effect on changing the academic landscape, that also shines across the whole country, its economy and society. In May 2009 the federal and state governments decided to continue the Excellence Initiative beyond 2012, providing a total of 2.7 billion Euros for the second five-year phase from 2012-2017. Graduate schools play a key role not only in developing internationally competitive centers of top-level research and scientific excellence in Germany but also in increasing their recognition and prestige. They serve as an instrument of quality assurance in promoting young researchers and are based on the principle of training outstanding doctoral students within an excellent research environment. Clusters of excellence will enable German university locations to establish internationally visible, competitive research and training facilities, thereby enhancing scientific networking and cooperation among the participating institutions. The Excellence Initiative provides funding for Institutional strategies that are aimed at developing top-level university research in Germany and increasing its competitiveness at an international level. Institutional Strategies aim to strengthen a university as a whole, so that it can compete successfully with the leading players in the international science market. An Institutional Strategy calls for a university to develop a long-term strategy on how it can consistently expand and enhance its cutting-edge research and improve the promotion of young scientists and researchers. This means identifying existing strengths and sharpening profiles in all fields. To qualify for the third funding line, universities have to develop an exceptional Institutional Strategy and must, additionally, each have at least one Graduate School and one Cluster of Excellence. Under the Excellence Initiative, a total of nine universities and their Institutional Strategies are funded for five years: Ludwig-Maximilians-Universität Munchen (LMU Munich), Technische Universität Munchen (TU Munich), Rheinisch-Westfaelische Technische Hochschule Aachen (RWTH Aachen), Universität Freiburg, Universität Konstanze, Universität Heidelberg, Universität Karlsruhe and Georg-August-Universität.

In France, in 2006 it began the initiative of the so called Poles of Investigation and of Higher Education-PRES- (Pôles de recherche et d'enseignement supèrieur) with the aim to extend and reinforce the top formation and the investigation to be a way to take place in the scientific international competition. Between 2007 and 2010, 17 PRES has been composed by 51 universities and other 51 organisms of investigation and public institutions (engineers' schools, hospital centers and territorial collectivities, between others). The creation of the PRES has been a previous fundamental step for L'Opération Campus, a national program for the aggregation and merger of universities to create internationally high ranking universities. The PRES has two missions: (i) to prepare, between the charter members the conditions of the merger of the universities, (ii) to guarantee the governance and L'Opération Campus's followup inside the frame of his mission, the PRES has to assemble the university group and (iii) to organize the cooperation between partners and to reinforce the competitiveness of the territory bringing the academic world over to the industrial world. Launched in February 2008, the Operation Campus is a multi-billion-euro investment program ( 5 billion Euros) with the goal 
to attract the best researchers and students and place France among the top universities in the world. Through a massive investment, this program aims to elevate France's university campuses to the highest international standards. With this initiative, urgency for building renovations making campuses more user-friendly and involvement with regional authorities and businesses it is required. The twelve successful projects chosen under the Operation Campus were selected based on the following four criteria: scientific and educational scope and reach; degree of urgency in the need for renovation of facilities; the potential to provide student housing; and the likely impact of the project for the region, considered in light of its potential to complement competitiveness clusters, research networks, and the efforts of local governments. Among the benefits, successful projects received substantial extra funds for construction, upgrading and maintenance of buildings, improving safety standards and making campuses more pleasant, user-friendly places in which to live. The twelve projects are located in Aix-Marseille, Bordeaux, Condorcet-Paris-Aubervilliers, Grenoble, Lille, Lorraine, Lyon, Montpellier, Paris intra-muros, Saclay, Strasbourg and Toulouse. With these commitments, the state reaffirmed more than ever its support to universities and research and its willingness to promote, within France and in international competition, major university centers founded on the regrouping of establishments, the sharing of skill and talent, and the notable improvement of living conditions for students. For ranking the excellence French universities, the project located in Paris intra-muros is not taken into account in this study because the Minister for Higher Education and Research considered this project as an exceptional case for the expansion and renovation of the Parisians Universities. Thus, under the Operation Campus a total of 33 excellence universities are selected: Universite de Provence (Aix-Marseille1), Université de la Mediterranée (Aix-Marseille2), Université Paul Cézanne (Aix-Marseille3), Université d'Avignon et des Pays de Vaucluse (Avignon), Université de Sciences Technologies de Bourdeaux (Bourdeaux1), Université Victor Segalen (Bourdeaux2), Université Michel de Montaigne (Bourdeaux3), Université Montesquieu (Bourdeaux4), Université de Pau et des Pays de l'Adour (UPPA), Université Joseph Fourier (Grenoble1), Université Pierre Mendès France (Grenoble2), Université Stendhal (Grenoble3), Université Lille1 Sciences et Technologies, Université Lille2 Droit et Santé, Université Charles de Gaulle (Lille3), Université Claude Bernard (Lyon1), Université Lumière (Lyon2), Université Jean Moulin (Lyon3), Université Montpellier1, Université Montpellier2 Sciences et Techniques, Université Paul-Valéry (Montpellier3), Université Paul Verlaine (Metz), Université Henri Poincaré (Nancy1), Nancy-Université (Nancy2), Université Paris 1 Panthéon-Sorbonne, Université

Vincennes-Saint-Denis (Paris8), Université Paris Nord (Paris13), Université de Strasbourg, Université Toulouse1 Capitole, Université de Toulouse - Le Mirail (Toulouse2), Université Paul Sabatier (Toulouse3), Université Paris Sud-11, and Université de Versailles SaintQuentin-en-Yvelines (L'UVSQV).

Unlike most of the popular rankings we do not follow the construction of rankings based on a final composite indicator obtained by aggregation of the composite indicators representative of the different features of the institutions activity (profile, sustainability, teaching, research, knowledge transfer, resources, and community engagement). Our goal is to build robust rankings for each area of activity considered.

To illustrate the proposed robust analysis techniques in building composite indicators, we rank the French and German universities of excellence across two broad categories related to the mission and vision of higher education institutions: Academic Profile and Institutional Sustainability. 


\subsection{Simple indicators for building composite indicators}

For assessing the Academic Profile of a university, it is necessary to establish the role and relative importance of the institution regionally, nationally and internationally in order to acquire a solid understanding of the university's enrolment prospects. Therefore, understanding the relative academic strengths of the institutions and the primary factors likely to influence enrolment going forward is paramount in understanding its financial prospects. In the analysis of Sustainability, emphasis is placed on the financial obligations carried by the university in relation to the financial resources currently available of the institutions. In a similar viewpoint as the CHE'ranking, we provide a multidimensional ranking in which single subjects (categories) are presented separately. In order to evaluate the Academic Profile of the institutions we examined a set of variables that were possible to

measure at all the institutions and finally this category include four simple indicators: (i) percentage of foreign students, (ii) percentage of academic staff with a $\mathrm{PhD}$ degree, (iii) percentage of graduate studies (official Master's and $\mathrm{PhD}$ ) and (iv) percentage of graduate students (enrolled in official Master's and $\mathrm{PhD}$ ).

Foreign students. That is, the proportion of students with a foreign nationality to the number of full-time students in the academic course 2007/2008. For French and German institutions this information is collected from the websites and reports of the institutions.

Academic Staff with a Ph.D. Represents the proportion of Doctors from full-time staff number in the academic course 2007/2008. This simple indicator has been constructed using the information published by the French Ministere de l'Enseignement Superieur et de la Recherche (MESR) and the websites and reports of the German institutions.

Graduate Studies. Includes official Master's and $\mathrm{PhD}$ courses offered by the institutions in the academic course 2007/2008 relative to the overall official studies. We decide to consider only official studies just because the non-official studies are measured by different credits, duration, etc., which difficult the comparison between them. For French institutions this information is collected from their websites and reports. For German institutions, the information comes from the German Statistisches Bundesamt.

Graduate Students. Represents the students who are enrolled in graduate studies, that is, in official Master's and $\mathrm{PhD}$ courses in the academic course 2007/2008 relative to the total number of students enrolled in official courses (undergraduate and graduate studies). In both cases, the information comes from the websites and reports of the institutions.

In a second ranking, the Sustainability of the institutions is examined by looking at the simple indicators: (i) third-party funding/total funding, (ii) employer's expenses (nonacademic and academic staff support)/total funding, (iii) total funding/undergraduate students and (iv) total funding/total students.

Third-party funding/total funding. This simple indicator represents the income that institutions receive for research from different public and private institutions. In Germany, this funding comes from the German Research Foundation (DGF), the Federal Government, the European Union, Industry and others (donations, sponsoring, etc.). Data collected corresponds to 2008, the latest published information at the websites and reports of the institutions. In France, third-party funding comes from the French Research National Agency (ANR), Territorial Collectivities, the European Union, Organisms of Recherche (CNRS, 
INSERM), Industry and others. This simple indicator corresponds to 2009 due to the information for 2008 was not available. This information is provided by the French Ministere de l'Enseignement Superieur et de la Recherche (MESR).

Employer's expenses. Represents the non-academic and academic expenses supported by the institutions, relative to the total funding received by the institutions. It represents the personal financial obligations carried by the university in relation to the financial resources. This simple indicator uniquely is available for French institutions (2009), and is reported by the MESR.

Total funding/undergraduate students. This simple indicator reflects the financial resources that institutions can arrange for his undergraduate students in facilities, investments and others. For French institutions, the information comes from the MESR (2009) and for German institutions comes from their websites and reports (2008).

Total funding/total students. This simple indicator reflects the financial resources that institutions receive relative to the size of the institution measure as number of students enrolled in the university. The sources of information are the same as the previous simple indicator.

Next, the data collected from the institutions is normalized as follows. Let consider a simple indicator $X_{j}$. If the larger the value, the better the performance of the institution (for example, the percent of academic staff with a $\mathrm{PhD}$ degree), then we normalize the simple indicator as follows

$$
I_{j}=100 \times \frac{X_{j}}{\max \left\{X_{j}\right\}},
$$

otherwise, if the smaller value, the better performance of the institution (for example, employer's expenses/total funding), then we normalize the simple indicator as follows,

$$
I_{j}=100 \times \frac{\min \left\{X_{j}\right\}}{X_{j}} .
$$

In this way the maximum in each category, assigned to the best institution, is 100 points and the rest of the institutions have scores according to their distance to the best. Once we get the set of $p$ normalized simple indicators $\mathrm{I}_{1}, \ldots, \mathrm{I}_{\mathrm{p}}$ the weights $\mathrm{w}_{1}, \ldots, \mathrm{w}_{\mathrm{p}}$ are calculated under the assumption that there is no external information about the weighting coefficients. In this context, in absence of higher education expert opinions and excluding statistical models, the initial vector of weights is computed as $\mathrm{w}_{(0)}=(1 / p, \ldots, 1 / p)$ following a principle of uniformity. Essentially, the true impact that a given simple indicator has on assessing the quality of the institutions is really difficult to measure objectively, thus, an interesting alternative is to assume that all the indicators have the same impact on the ranking and generate small perturbations around this initial vector. Under this simulation scheme a plurality of scenarios that represent a wide range of weights is considered, making the ranking more robust.

A key question arises about the level of perturbation s. How dependent is the position of the ranked institution to the chosen value of s?. First of all, the level of perturbation should be small since high values of $\mathrm{s}$ would remove us from the principle of uniformity in the weights that we propose in absence of higher education expert opinions. Secondly, the higher the level of perturbation the higher the impact of the simple indicators's variability in the distribution of the composite indicator. In this sense, trying give answer to the proposed 
question we consider different values of $\mathrm{s}$ and search how the ranked institutions react under small changes in the values of s. As one can observe from Appendix 2, the ranked positions achieved by the French universities almost remain unchanged no matter the perturbations introduced in the weights. Only the expected ranked positions in the range [ $5^{\text {th }}$-quantile, $95^{\text {th }}$ quantile] for a level of perturbation about $30 \%$ of $\mathrm{w}_{\mathrm{j}}$ present small differences for some universities. For the German universities, the ranked positions remain unchanged. Based on these results, we propose to consider perturbations about $20 \%$ or $25 \%$ of $\mathrm{w}_{\mathrm{j}}$, that is, $\mathrm{s}=0.2 \times \mathrm{w}_{\mathrm{j}}$ or $\mathrm{s}=0.25 \times \mathrm{w}_{\mathrm{j}}$ (in this application we use the $20 \%$ ) and generate $m=100$ uniform values, $\mathrm{w}^{(\mathrm{i})}$, over the interval $[(1 / p)-\mathrm{s},(1 / p)+\mathrm{s}]$. At this point, the underlying composite indicators $\mathrm{CI}_{\mathrm{i}}$ are calculated and the institutions are ranked according to these values. The robust ranking based on random simulation (with $s=0.2 \times 1 / p$ ) of excellence French universities in the framework of Academic Profile and Sustainability are shown in Tables 1 and 2, respectively. These tables display the university ranks using the initial vector of weights, the median rank and the corresponding 5 th and 95 th percentiles of the distribution of its rankings. Tables 3 and 4 show the excellence German university rankings.

From the evaluation of the Academic Profile of the French universities it is clear that Paris8, Paris1, Strasbourg and Montpellier1 are the Top 4 universities that remain undoubtedly in the first four positions when small perturbations around the initial vector of weights are generated. As we move towards the middle ranked universities, the impact of perturbations on the rank becomes more pronounced for some institutions. For example, the University of Paris 13 , which is ranked in the $8^{\text {th }}$ position when using uniform weights, has a very uncertain position when acknowledging the perturbations: it could be ranked anywhere between $5^{\text {th }}$ and $11^{\text {th }}$ position. The case of the University of Paris 11 offers another pronounced example. In this case, we discover that although the University of Paris 11 has a very good score in three of the four simple indicators, it has a percentage of foreign students smaller than one can expect according to the rest of its scores. Thus, the higher the percentage weighting of foreign students, the lower the value of the composite indicator, which results in a worst position in the ranking. Universities that are ranked in the lower end have a small degree of impact in their positions, just because these institutions have the lowest scores in all the simple indicators, thus, independently of the weights they will be the worst in the ranking. About the Sustainability of the institutions, it is interesting to observe that the impact of perturbations on the rank becomes more weaker than in the previous observed ranking. This result suggests that the performance of the institutions in all simple indicators are quite similar. For German institutions it is clear that their positions in the ranking almost remain unchanged no matter the perturbations introduced in the weights. Figures 1 to Figure 4 display the median (blue point) and the corresponding $5^{\text {th }}$ and 95th percentiles (bounds) of the distribution of the composite indicator for French and German universities when evaluating the Academic Profile and Sustainability. Next, the results obtained in Tables 1 and 3 are discussed in comparison with the university ranking obtained when using the integrative weights proposed by Ding and Qiu (2011). There are two kind of integrative approach: "additive integration" and "multiplicative integration". When using uniform weights as subjective weights, we obtain that the "multiplicative integration" is just the subjective weights. Ding and Qiu define the objective weight of each simple indicator in terms of the contribution of its variation coefficient to the total variability (computed as the total sum of variation coefficients). The new weights obtained in ranking the French and German universities of excellence in the Academic Profile are shown in Tables 5 and 6, respectively. 
Table 1. Robust ranking for evaluating the Academic Profile performance of the excellence French universities

\begin{tabular}{|c|c|c|c|}
\hline University & $\begin{array}{c}\text { Rank using } \\
\text { uniform weights }\end{array}$ & Median Rank & {$\left[5^{\text {th }}\right.$ quantile, $95^{\text {th }}$ quantile] } \\
\hline Paris8 & 1 & 1 & {$[1,1]$} \\
\hline Paris1 & 2 & 2 & {$[2,2]$} \\
\hline Strasbourg & 3 & 3 & {$[3,4]$} \\
\hline Montpellier1 & 4 & 4 & {$[3,5]$} \\
\hline Paris11 & 5 & 5 & {$[4,10]$} \\
\hline Aix1 & 6 & 6 & {$[5,9]$} \\
\hline Aix 3 & 7 & 7 & {$[5,8]$} \\
\hline Grenoble3 & 8 & 9 & {$[7,12]$} \\
\hline Montpellier3 & 8 & 9 & {$[7,12]$} \\
\hline Paris13 & 8 & 9 & {$[5,11]$} \\
\hline Toulouse1 & 11 & 11 & {$[8,13]$} \\
\hline Lille1 & 12 & 12 & {$[9,13]$} \\
\hline Bourdeaux2 & 13 & 13 & {$[10,14]$} \\
\hline Lyon3 & 14 & 14 & {$[13,14]$} \\
\hline Aix2 & 15 & 15 & {$[15,15]$} \\
\hline Bourdeaux1 & 16 & 16 & {$[16,18]$} \\
\hline Grenoble2 & 17 & 17 & {$[16,19]$} \\
\hline Lyon2 & 17 & 17 & {$[16,19]$} \\
\hline Grenoble1 & 19 & 19 & {$[18,19]$} \\
\hline Lyon1 & 20 & 20 & {$[20,20]$} \\
\hline Montpellier2 & 21 & 21 & {$[21,21]$} \\
\hline Toulouse 2 & 22 & 22 & {$[22,22]$} \\
\hline Bourdeaux4 & 23 & 23 & {$[23,25]$} \\
\hline Nancy2 & 24 & 24 & {$[23,25]$} \\
\hline Bourdeaux3 & 25 & 25 & {$[23,25]$} \\
\hline Pau & 26 & 26 & {$[26,27]$} \\
\hline Toulouse3 & 27 & 27 & {$[26,29]$} \\
\hline Lille2 & 28 & 28 & {$[27,29]$} \\
\hline Metz & 29 & 29 & {$[27,30]$} \\
\hline Versailles & 30 & 30 & {$[29,30]$} \\
\hline Avignon & 31 & 31 & {$[31,31]$} \\
\hline Lille3 & 32 & 32 & {$[32,33]$} \\
\hline Nancy1 & 33 & 33 & {$[32,33]$} \\
\hline
\end{tabular}

Tables 7 and 8 show the French and German university ranking using each kind of weights, respectively. From Table 5 and Table 6 one can observe that the higher the variability of the simple indicator, the higher the value of its weight in both, the "additive integration" and the "additive integration two", moving away from the subjective weight. We believe that with a small number of simple indicators the final ranking will have a great bias because any university with a very good performance in the indicator with highest variability and a worse performance in the others will have a better position than other universities with a good performance in all the indicators. Alternatively, if we are interested in taking into account the variability of the indicators as Ding and Qiu propose, we can introduce the following change in the simulation process. Suppose that the simple indicator with highest variability should have the highest weight, $\mathrm{w}_{\mathrm{j}}$. In such a case, one can include a restriction over that weight in the simulation process, for instance, $(1 / p)<\mathrm{w}_{\mathrm{j}}<a$, where $(1 / p)$ is the subjective weight and $a$ is the coefficient of variation of that simple indicator. With this restriction we can include an objective consideration about that simple indicator but the final ranking is based on a range bracket of weights determined by subjective and objective consideration, instead of a ranking highly influenced by the simple indicator with highest variability. 
Table 2. Robust ranking for evaluating the Sustainability performance of the excellence French universities

\begin{tabular}{|c|c|c|c|}
\hline University & $\begin{array}{c}\text { Rank using } \\
\text { uniform weights }\end{array}$ & Median Rank & {$\left[5^{\text {th }}\right.$ quantile, $95^{\text {th }}$ quantile $]$} \\
\hline Paris11 & 1 & 1 & {$[1,1]$} \\
\hline Grenoble1 & 2 & 2 & {$[2,2]$} \\
\hline Strasbourg & 3 & 3 & {$[3,3]$} \\
\hline Bourdeaux1 & 4 & 4 & {$[4,4]$} \\
\hline Lyon1 & 5 & 5 & {$[5,7]$} \\
\hline Montpellier2 & 6 & 6 & {$[5,7]$} \\
\hline Aix2 & 7 & 7 & {$[5,7]$} \\
\hline Nancy1 & 8 & 8 & {$[8,9]$} \\
\hline Toulouse3 & 9 & 9 & {$[8,9]$} \\
\hline Bourdeaux2 & 10 & 10 & {$[10,10]$} \\
\hline Lille1 & 11 & 11 & {$[11,11]$} \\
\hline Pau & 12 & 12 & {$[12,12]$} \\
\hline Aix1 & 13 & 13 & {$[13,14]$} \\
\hline Aix3 & 14 & 14 & {$[14,16]$} \\
\hline Montpellier1 & 15 & 15 & {$[13,16]$} \\
\hline Versailles & 16 & 16 & {$[14,16]$} \\
\hline Lille2 & 17 & 17 & {$[17,17]$} \\
\hline Grenoble2 & 18 & 18 & {$[18,19]$} \\
\hline Avignon & 19 & 19 & {$[18,19]$} \\
\hline Paris13 & 20 & 20 & {$[20,20]$} \\
\hline Bourdeaux4 & 21 & 21 & {$[21,23]$} \\
\hline Grenoble3 & 22 & 22 & {$[21,23]$} \\
\hline Metz & 23 & 23 & {$[21,23]$} \\
\hline Lyon2 & 24 & 24 & {$[24,24]$} \\
\hline Toulouse1 & 25 & 25 & {$[25,25]$} \\
\hline Toulouse 2 & 26 & 26 & {$[26,27]$} \\
\hline Lyon3 & 27 & 27 & {$[26,27]$} \\
\hline Paris8 & 28 & 28 & {$[28,28]$} \\
\hline Lille3 & 29 & 29 & {$[29,29]$} \\
\hline Montpellier3 & 30 & 30 & {$[30,30]$} \\
\hline Nancy2 & 31 & 31 & {$[31,32]$} \\
\hline Bourdeaux3 & 32 & 32 & {$[31,33]$} \\
\hline Paris1 & 33 & 33 & {$[32,33]$} \\
\hline
\end{tabular}

Table 3. Robust ranking for evaluating the Academic Profile performance of the excellence German universities

\begin{tabular}{|l|c|c|c|}
\hline \multicolumn{1}{|c|}{ University } & $\begin{array}{c}\text { Rank using } \\
\text { uniform weights }\end{array}$ & Median Rank & [5 $^{\text {th }}$ quantile, 95 ${ }^{\text {th }}$ quantile $]$ \\
\hline Heidelberg & 1 & 1 & {$[1,1]$} \\
\hline Fu Berlin & 2 & 2 & {$[2,3]$} \\
\hline Göttingen & 3 & 3 & {$[2,4]$} \\
\hline TUMunich & 4 & 4 & {$[3,4]$} \\
\hline RWTHAachen & 6 & 5 & {$[5,6]$} \\
\hline Constance & 5 & 6 & {$[5,6]$} \\
\hline LMUMunich & 7 & 7 & {$[7,7]$} \\
\hline Freiburg & 8 & 8 & {$[8,9]$} \\
\hline Karlsruhe & 9 & 9 & {$[8,9]$} \\
\hline
\end{tabular}


Table 4. Robust ranking for evaluating the Sustainability performance of the excellence German universities

\begin{tabular}{|l|c|c|c|}
\hline \multicolumn{1}{|c|}{ University } & $\begin{array}{c}\text { Rank using } \\
\text { uniform weights }\end{array}$ & Median Rank & [5 $^{\text {th }}$ quantile, 95 ${ }^{\text {th }}$ quantile $]$ \\
\hline TUMunich & 1 & 1 & {$[1,1]$} \\
\hline Karlsruhe & 2 & 2 & {$[2,2]$} \\
\hline RWTHAachen & 3 & 3 & {$[3,3]$} \\
\hline Constance & 4 & 4 & {$[4,4]$} \\
\hline Freiburg & 5 & 5 & {$[5,6]$} \\
\hline Göttingen & 6 & 6 & {$[5,6]$} \\
\hline Heidelberg & 7 & 7 & {$[7,7]$} \\
\hline FUBerlin & 8 & 8 & {$[8,8]$} \\
\hline LMUMunich & 9 & 9 & {$[9,9]$} \\
\hline
\end{tabular}

Tables 7 and 8 show that the differences between ranks using the integrative approach and the random simulation are bigger for the French universities. Particularly, when the variation coefficient of some simple indicator is much bigger than the others (as we can observe in the objective weights), this implies that institutions with a good (or bad) performance in that simple indicator will obtain a better (or worst) ranking in the additive integration, whereas with the random simulation they neither rewards nor penalizes for a single simple indicators, as explained before. As an illustration, the university of Aix 1 has one of the lowest percentages of foreign students, whereas it has a very good performance in the rest of simple indicators. Thus, using the "additive integration" this university is ranked in the $11^{\text {th }}$ position whereas with the random simulation it is ranked between the $5^{\text {th }}$ and $9^{\text {th }}$ position. The case of the University of Paris 11 and Paris 13 offer another pronounced examples. This impact on the German universities becomes more weaker because the performance of the institutions in all simple indicators are quite similar and the fluctuations of the simple indicators not influence the final ranking.

It is important to note that if we are interested in defining weights that highlights the differences between institutions instead of uniform weights, a simple way to measure the variability of the data is using some measure of global variability. In this way, the relevance of each simple indicator can be defined in terms of the contribution of its variance to the total variability. Then, this initial vector of weights can be used to generate random simulation around it and there is no bias in the selection of weight's vector due to subjective criteria.

We may conclude that our random simulation approach is general enough to include all the analysis carried out if Ding and Qiu's proposal is followed. 


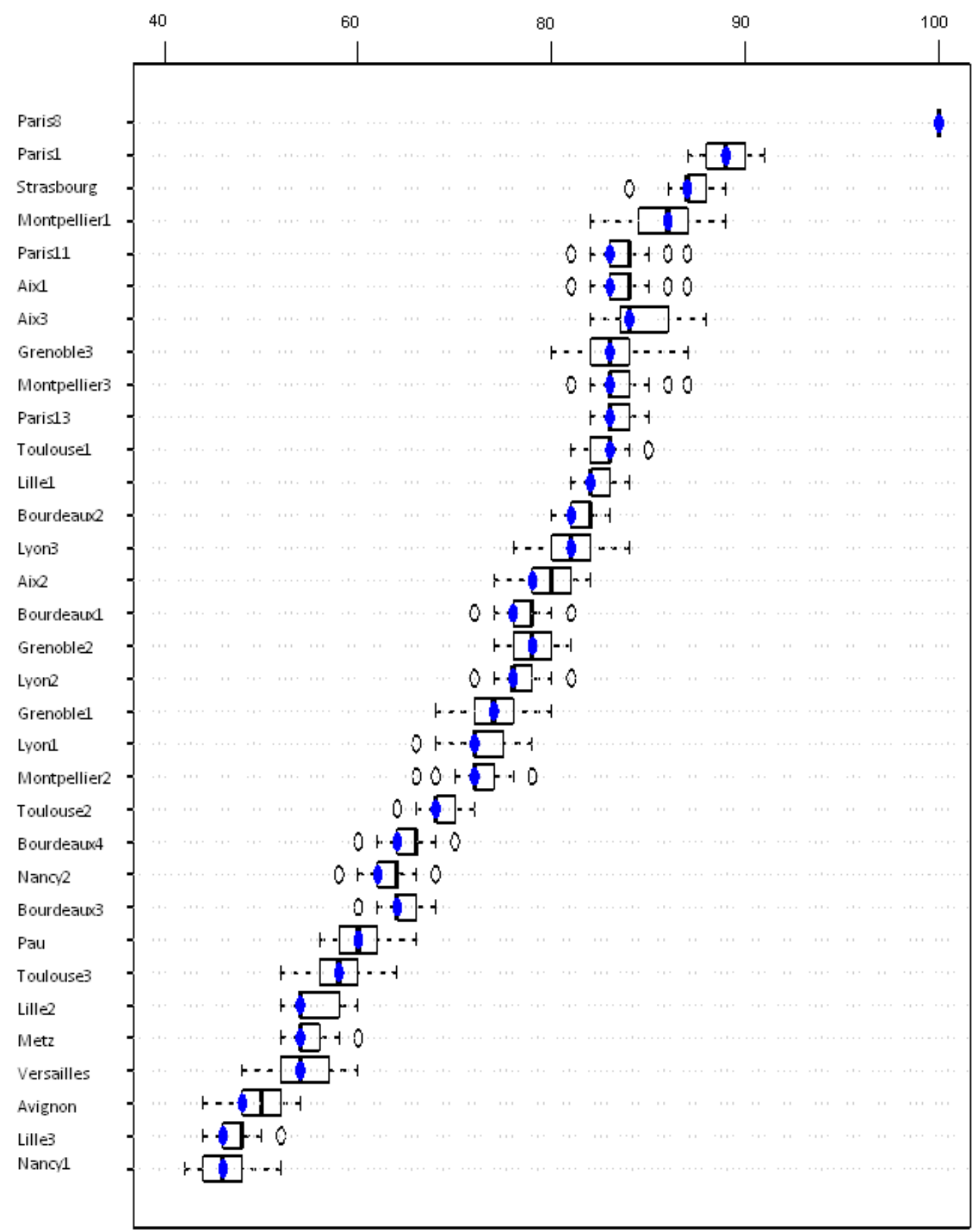

Figure 1. Composite indicator using uniform weights (blue point) and the corresponding distribution of the composite indicator (box) for the excellence French institutions in the framework of Academic Profile. 


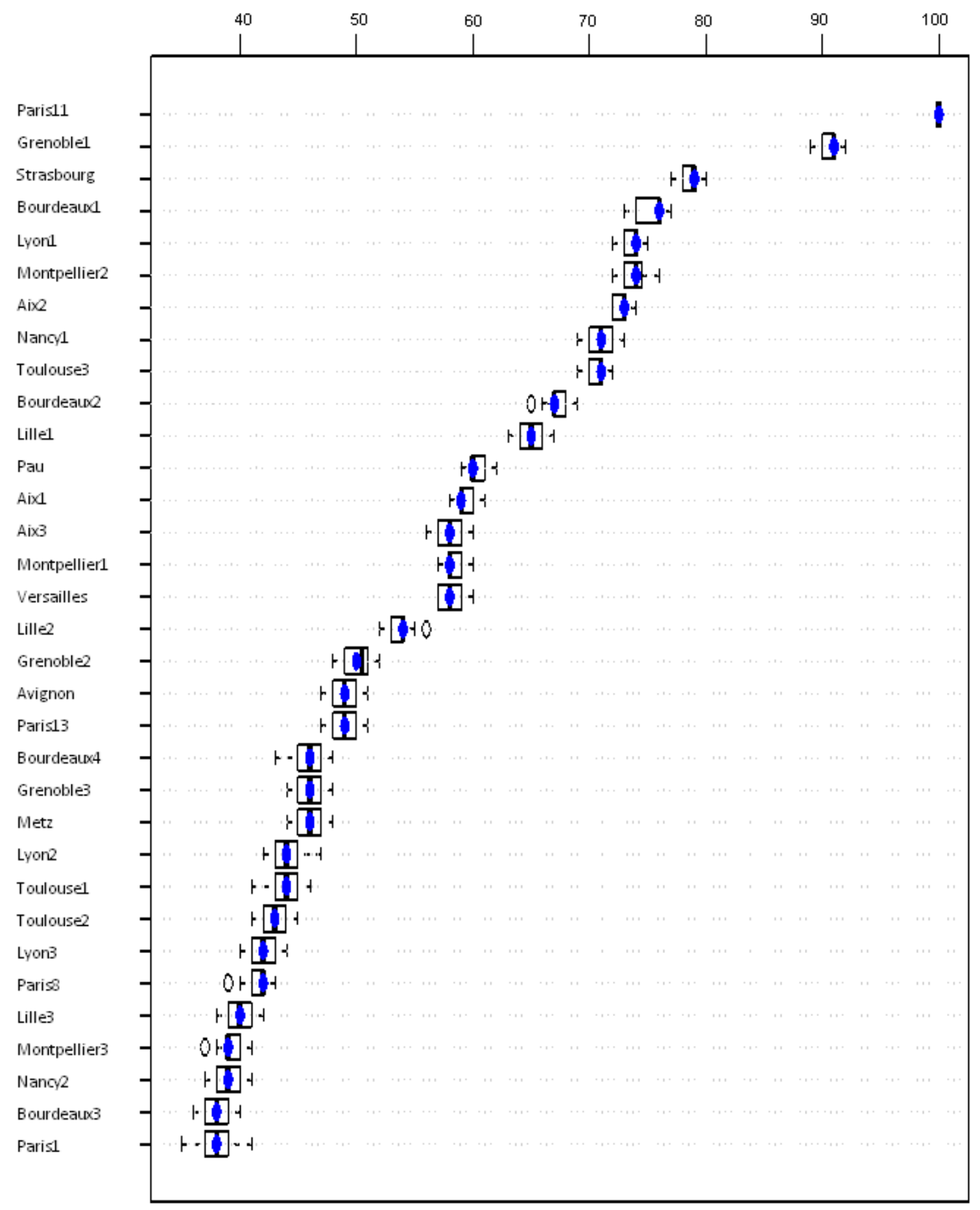

Figure 2. Composite indicator using uniform weights (blue point) and the corresponding distribution of the composite indicator (box) for the excellence French institutions in the framework of Sustainability. 


\section{Composite Indicator}

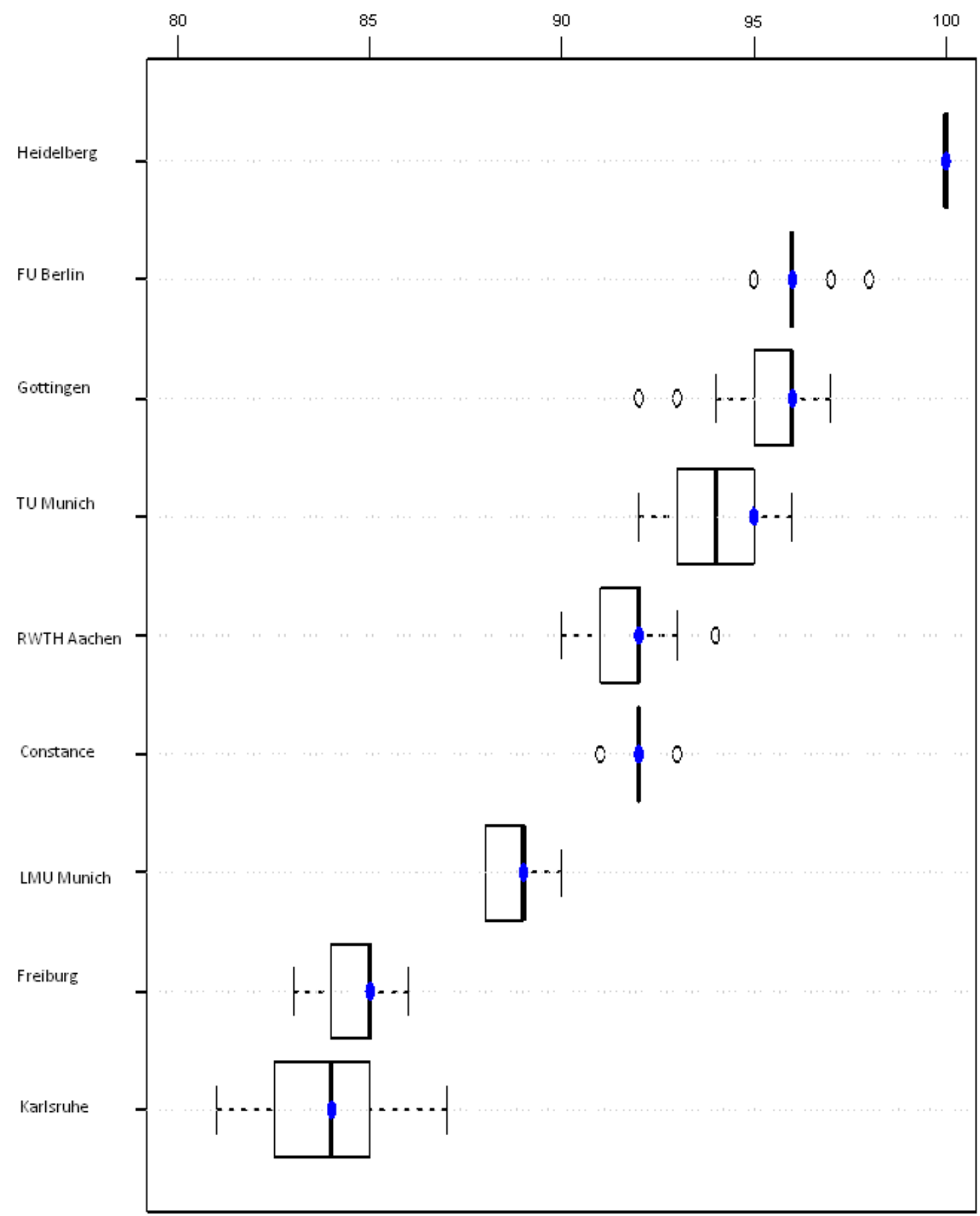

Figure 3. Composite indicator using uniform weights (blue point) and the corresponding distribution of the composite indicator (box) for the excellence German institutions in the framework of Academic Profile. 
Composite Indicator

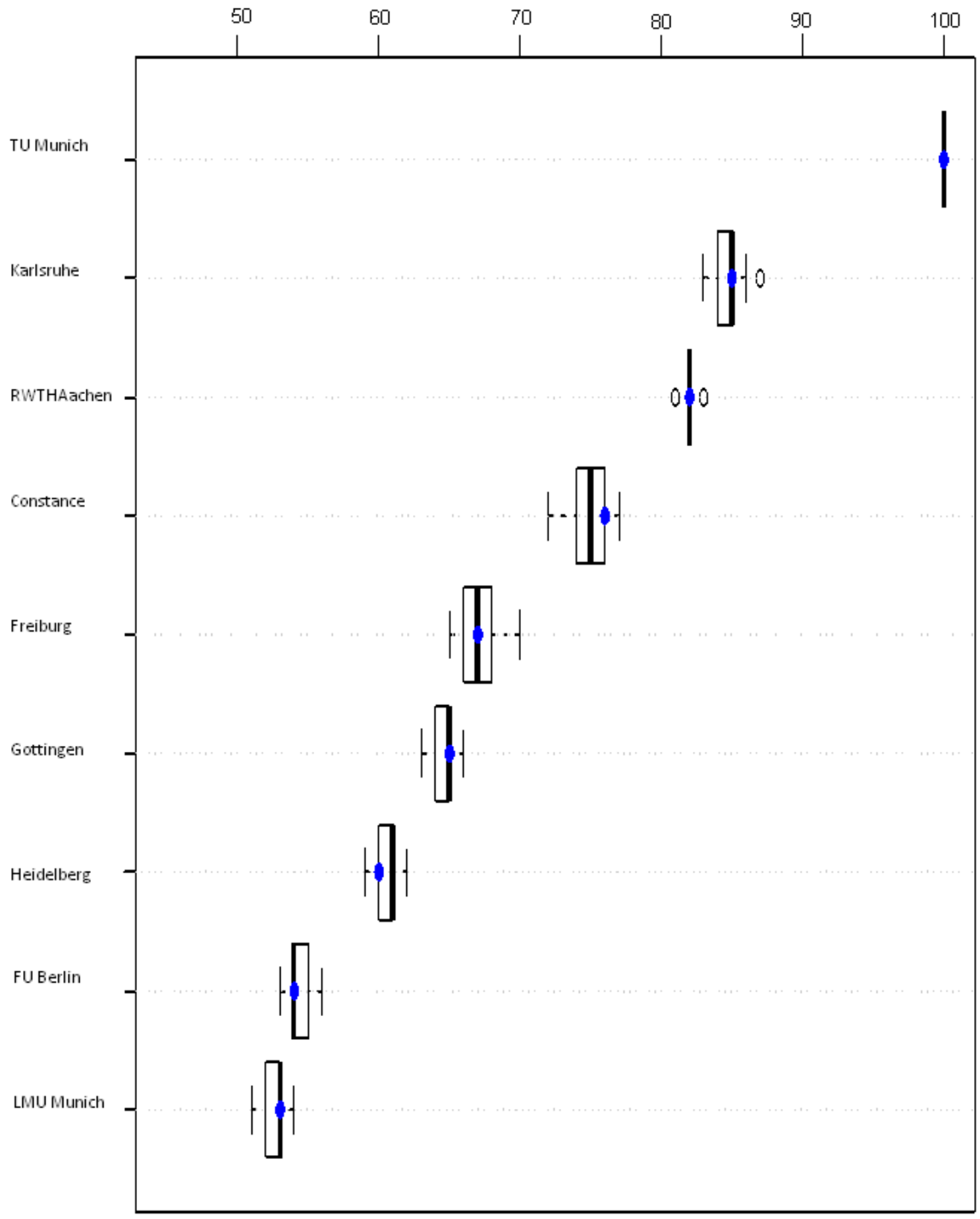

Figure 4. Composite indicator using uniform weights (blue point) and the corresponding distribution of the composite indicator (box) for the excellence German institutions in the framework of Sustainability. 
Table 5. The indicator weights obtained by various kind of approach (Ding and Qiu) for ranking French universities.

\begin{tabular}{|l|c|c|c|c|}
\hline \multicolumn{1}{|c|}{ Simple indicator } & $\begin{array}{c}\text { Subjective } \\
\text { weight }\end{array}$ & $\begin{array}{c}\text { Objective } \\
\text { weight }\end{array}$ & $\begin{array}{c}\text { Additive } \\
\text { integration }\end{array}$ & $\begin{array}{c}\text { Additive integration } \\
\text { two }\end{array}$ \\
\hline Foreign students & 0.25 & 0.580 & 0.522 & 0.415 \\
\hline Academic staff with a Ph.D & 0.25 & 0.049 & 0.237 & 0.149 \\
\hline Graduate studies & 0.25 & 0.245 & 0.343 & 0.248 \\
\hline Graduate students & 0.25 & 0.126 & 0.278 & 0.188 \\
\hline
\end{tabular}

Table 6. The indicator weights obtained by various kind of approach (Ding and Qiu) for ranking the German universities.

\begin{tabular}{|l|c|c|c|c|}
\hline \multicolumn{1}{|c|}{ Simple indicator } & $\begin{array}{c}\text { Subjective } \\
\text { weight }\end{array}$ & $\begin{array}{c}\text { Objective } \\
\text { weight }\end{array}$ & $\begin{array}{c}\text { Additive } \\
\text { integration }\end{array}$ & $\begin{array}{c}\text { Additive integration } \\
\text { two }\end{array}$ \\
\hline Foreign students & 0.25 & 0.353 & 0.374 & 0.301 \\
\hline Academic staff with a Ph.D & 0.25 & 0.008 & 0.231 & 0.129 \\
\hline Graduate studies & 0.25 & 0.554 & 0.458 & 0.402 \\
\hline Graduate students & 0.25 & 0.085 & 0.263 & 0.168 \\
\hline
\end{tabular}

Table 7. Ranking for French Excellence universities in the academic profile using various kind of approach.

\begin{tabular}{|c|c|c|c|c|c|}
\hline \multirow[b]{2}{*}{ University } & \multicolumn{4}{|c|}{ Ranks using the weights proposed by Ding and Qiu (2011) } & \multirow{2}{*}{$\begin{array}{c}\text { Ranks with the random } \\
\text { simulation } \\
\left.\mathbf{5}^{\text {th }} \text { quantile, } \mathbf{9 5}^{\text {th }} \text { quantile }\right]\end{array}$} \\
\hline & $\begin{array}{l}\text { Subjective } \\
\text { weights }\end{array}$ & $\begin{array}{l}\text { Objective } \\
\text { weights }\end{array}$ & $\begin{array}{c}\text { Additive } \\
\text { integration }\end{array}$ & $\begin{array}{c}\text { Additive } \\
\text { integration two }\end{array}$ & \\
\hline Aix1 & 6 & 12 & 11 & 11 & {$[5,9]$} \\
\hline Aix2 & 15 & 16 & 15 & 15 & {$[15,15]$} \\
\hline Aix3 & 7 & 9 & 7 & 9 & {$[5,8]$} \\
\hline Avignon & 31 & 32 & 31 & 31 & {$[31,31]$} \\
\hline Bourdeaux1 & 17 & 19 & 18 & 18 & {$[16,18]$} \\
\hline Bourdeaux2 & 13 & 20 & 17 & 17 & {$[10,14]$} \\
\hline Bourdeaux3 & 25 & 26 & 25 & 25 & {$[23,25]$} \\
\hline Bourdeaux4 & 23 & 21 & 23 & 22 & {$[23,25]$} \\
\hline Grenoble1 & 19 & 22 & 19 & 19 & {$[18,19]$} \\
\hline Grenoble2 & 18 & 10 & 14 & 14 & {$[16,19]$} \\
\hline Grenoble3 & 8 & 13 & 12 & 12 & {$[7,12]$} \\
\hline Lille1 & 12 & 6 & 8 & 7 & {$[9,13]$} \\
\hline Lille2 & 28 & 25 & 28 & 26 & {$[27,29]$} \\
\hline Lille3 & 32 & 33 & 33 & 33 & {$[32,33]$} \\
\hline Lyon1 & 20 & 24 & 21 & 23 & {$[20,20]$} \\
\hline Lyon2 & 16 & 15 & 16 & 16 & {$[16,19]$} \\
\hline Lyon3 & 14 & 8 & 9 & 8 & {$[13,14]$} \\
\hline Montpellier1 & 4 & 11 & 10 & 10 & {$[3,5]$} \\
\hline Montpellier2 & 21 & 17 & 20 & 20 & {$[21,21]$} \\
\hline Montpellier3 & 8 & 14 & 13 & 13 & {$[7,12]$} \\
\hline Metz & 29 & 27 & 30 & 29 & {$[27,30]$} \\
\hline Nancyl & 33 & 31 & 32 & 32 & {$[32,33]$} \\
\hline Nancy2 & 24 & 23 & 24 & 24 & {$[23,25]$} \\
\hline Paris1 & 2 & 3 & 2 & 2 & {$[2,2]$} \\
\hline Paris8 & 1 & 1 & 1 & 1 & {$[1,1]$} \\
\hline Paris11 & 5 & 7 & 6 & 6 & {$[4,10]$} \\
\hline Paris13 & 8 & 2 & 4 & 4 & {$[5,11]$} \\
\hline Pau & 26 & 30 & 26 & 28 & {$[26,27]$} \\
\hline Strasbourg & 3 & 5 & 3 & 3 & {$[3,4]$} \\
\hline Toulouse1 & 11 & 4 & 5 & 5 & {$[8,13]$} \\
\hline Toulouse2 & 22 & 18 & 22 & 21 & {$[22,22]$} \\
\hline Toulouse3 & 27 & 28 & 27 & 27 & {$[26,29]$} \\
\hline Versailles & 30 & 29 & 29 & 30 & {$[29,30]$} \\
\hline
\end{tabular}


Table 8. Ranking for German Excellence Universities in the academic profile using various kind of approach.

\begin{tabular}{|c|c|c|c|c|c|}
\hline \multirow[b]{2}{*}{ University } & \multicolumn{4}{|c|}{ Ranks using the weights proposed by Ding and Qiu (2011) } & \multirow{2}{*}{$\begin{array}{c}\text { Ranks with the random } \\
\text { simulation } \\
\left.\mathbf{5}^{\text {th }} \text { quantile, } \mathbf{9 5}^{\text {th }} \text { quantile }\right]\end{array}$} \\
\hline & $\begin{array}{c}\text { Subjective } \\
\text { weights }\end{array}$ & $\begin{array}{l}\text { Objective } \\
\text { weights }\end{array}$ & $\begin{array}{c}\text { Additive } \\
\text { integration }\end{array}$ & $\begin{array}{c}\text { Additive } \\
\text { integration two }\end{array}$ & \\
\hline Constance & 6 & 8 & 6 & 6 & {$[5,6]$} \\
\hline Freiburg & 8 & 7 & 8 & 8 & {$[8,9]$} \\
\hline FU Berlin & 2 & 4 & 3 & 3 & {$[2,3]$} \\
\hline Gottingen & 3 & 2 & 2 & 2 & {$[2,4]$} \\
\hline Heidelberg & 1 & 1 & 1 & 1 & {$[1,1]$} \\
\hline Karlsruhe & 9 & 9 & 9 & 9 & {$[8,9]$} \\
\hline LMU Munich & 7 & 6 & 7 & 7 & {$[7,7]$} \\
\hline RWTH Aachen & 5 & 3 & 4 & 4 & {$[5,6]$} \\
\hline TU Munich & 4 & 5 & 5 & 5 & {$[3,4]$} \\
\hline
\end{tabular}

\section{Conclusions and Extensions}

The combination of stochastic simulation to generate stochastic perturbations around any initial vector of weights and to rank universities in a range bracket provide a rigorous, balanced and transparent complement to other models of university rankings. We believe that ranking universities using a distribution of values instead of a simple number make the comparison between institutions more reliable. Furthermore we have implicitly assumed that there is no external information about the initial vector of weights used to generate perturbations. We might also have situations in which some knowledge exists on the weights, in that case, additional constrains can be introduced in the simulation scheme. Essentially leading to a situation where uncertainty in the weights of simple indicators is introduced and universities are ranked over a plurality of scenarios allows reducing the uncertainty associated with the assessment of a specific rank. The methodology proposed in this work is illustrated ranking the French and German universities of excellence in each of the two subject areas: Academic Profile and Institutional Sustainability. A first remark is that those institutions with similar normalized values in all simple indicators will have a very low variability in the composite indicator's final distribution. Furthermore, independently of the initial vector of weights they will be ranked in similar positions. On the contrary, when some institution has done a very good perform in all the simple indicators except at least one, in which has done a poor perform,

that institution will have a higher volatility in the composite indicator's final distribution and it will be shifted several positions in the ranking depending on the perturbations introduced in the weights' vector. In addition to the two algorithms proposed in this work for generating perturbations around the initial vector of weights, another stochastic simulation schemes could be analyzed. This allows for the option of searching for directions of maximum variability in the composite indicator's final distribution with a set of restrictions about the weights. These restrictions would reflect prior information about the weights or include requirement for each simple indicator to weight at least or no more that a fixed threshold.

By using the proposed robust and reliable techniques we have discovered some instabilities underlying in the ranked French and German universities of excellence that had remained invisible if the ranking had been built by standard techniques. 


\section{Appendix 1. Monte Carlo Schemes}

\section{Algorithm1}

(a) Let $\mathrm{w}^{(0)}=\left(\mathrm{w}_{1}, \ldots, \mathrm{w}_{\mathrm{p}}\right)$. Fix the radius $s$ and the sample size $m$.

(b) Generate $p$-1 uniform values $\mathrm{w}_{1}{ }^{(1)}, \ldots, \mathrm{w}_{\mathrm{p}-1}{ }^{(1)}$ on $\left(\mathrm{w}_{1}-\mathrm{s}, \mathrm{w}_{1}+\mathrm{s}\right),\left(\mathrm{w}_{2}-\mathrm{s}, \mathrm{w}_{2}+\mathrm{s}\right),, \ldots,\left(\mathrm{w}_{\mathrm{p}-1}-\mathrm{s}, \mathrm{w}_{\mathrm{p}-}\right.$

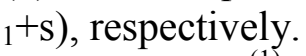

(c) If $\left(1-\left(\mathrm{w}_{1}{ }^{(1)}, \ldots, \mathrm{w}_{\mathrm{p}-1}{ }^{(1)}\right)\right) \in\left(\mathrm{w}_{\mathrm{p}}-\mathrm{s}, \mathrm{w}_{\mathrm{p}}+\mathrm{s}\right)$ then $\mathrm{w}^{(1)}=\left(\mathrm{w}_{1}{ }^{(1)}, \ldots, \mathrm{w}_{\mathrm{p}-1}{ }^{(1)}, 1-\left(\mathrm{w}_{1}{ }^{(1)}, \ldots, \mathrm{w}_{\mathrm{p}-1}{ }^{(1)}\right)\right)$, otherwise reject.

(d) Iterate steps b. and c. to get $\mathrm{w}^{(1)} \ldots \mathrm{w}^{(\mathrm{m})}$.

Figure 5 shows the corresponding surface in $\mathfrak{R}^{3}$ for the initial vector of weights $\mathrm{w}^{(0)}=(1 / 3,1 / 3,1 / 3)$ when the perturbations are generated around this point with $\mathrm{s}=0.2 \mathrm{w}_{\mathrm{j}}$ following Algorithm 1.

\section{Algorithm2}

(a) Let $\mathrm{w}^{(0)}=\left(\mathrm{w}_{1}, \ldots, \mathrm{w}_{\mathrm{p}}\right)$. Fix the radius $s$ and the sample size $m$.

(b) Generate $p$ uniform values $\mathrm{w}_{1}{ }^{(1)}, \ldots, \mathrm{w}_{\mathrm{p}}{ }^{(1)}$ on $\left(\mathrm{w}_{1}-\mathrm{s}, \mathrm{w}_{1}+\mathrm{s}\right),\left(\mathrm{w}_{2}-\mathrm{s}, \mathrm{w}_{2}+\mathrm{s}\right), \ldots,\left(\mathrm{w}_{\mathrm{p}}-\mathrm{s}, \mathrm{w}_{\mathrm{p}}+\mathrm{s}\right)$, respectively.

(c) If $\left(\mathrm{w}_{1}{ }^{(1)}\right)^{2}+\ldots+\left(\mathrm{w}_{\mathrm{p}}{ }^{(1)}\right)^{2} \leq \mathrm{s}^{2}$ and $\mathrm{w}_{1}{ }^{(1)}+\ldots+\mathrm{w}_{\mathrm{p}}{ }^{(1)}=1$, then $\mathrm{w}^{(1)}=\left(\mathrm{w}_{1}{ }^{(1)}, \ldots, \mathrm{w}_{\mathrm{p}}{ }^{(1)}\right)$, otherwise reject and re-select $p$ uniform values following step $b$.

(d) Iterate steps b. and c. to get $\mathrm{w}^{(1)} \ldots \mathrm{w}^{(\mathrm{m})}$.

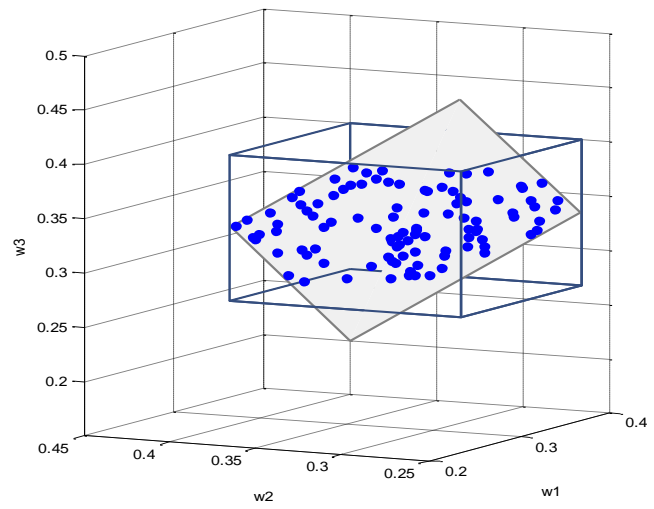

Figure5. Points randomly generated for the initial vector of weights $\mathrm{w}^{(0)}=(1 / 3,1 / 3,1 / 3)$ such as they live in the intersection of the 3-dimensional hypercube and the 2-simplex in $\mathrm{R}^{3}$. 


\section{Appendix 2. Robust ranking using different values of the level of perturbation.}

Table 9. Robust ranking for evaluating the Academic Profile performance of the excellence French universities using different values of the level of perturbation $\mathrm{s}$.

\begin{tabular}{|c|c|c|c|c|c|c|c|c|c|c|}
\hline & \multicolumn{5}{|c|}{ Median Rank } & \multicolumn{5}{|c|}{ [5th quantile, 95 th quantile] } \\
\hline & $\mathrm{s}=0.10 \mathrm{w}_{\mathrm{j}}$ & $\mathrm{s}=0.15 \mathrm{w}_{\mathrm{j}}$ & $\mathrm{s}=0.20 \mathrm{w}_{\mathrm{j}}$ & $\mathrm{s}=0.25 \mathrm{w}_{\mathrm{j}}$ & $\mathrm{s}=0.30 \mathrm{w}_{\mathrm{j}}$ & $\mathrm{s}=0.10 \mathrm{w}_{\mathrm{j}}$ & $\mathrm{s}=0.15 \mathrm{w}_{\mathrm{j}}$ & $\mathrm{s}=0.20 \mathrm{w}_{\mathrm{j}}$ & $\mathrm{s}=0.25 \mathrm{w}_{\mathrm{j}}$ & $\mathrm{s}=0.30 \mathrm{w}_{\mathrm{j}}$ \\
\hline Aix1 & 6 & 6 & 6 & 6 & 6 & {$\left[\begin{array}{ll}5 & 8\end{array}\right]$} & {$\left[\begin{array}{ll}5 & 8\end{array}\right]$} & {$\left[\begin{array}{ll}5 & 9\end{array}\right]$} & {$\left[\begin{array}{ll}5 & 9\end{array}\right]$} & {$\left[\begin{array}{ll}4 & 10\end{array}\right]$} \\
\hline Aix2 & 15 & 15 & 15 & 15 & 15 & {$\left[\begin{array}{ll}15 & 15\end{array}\right]$} & {$\left[\begin{array}{ll}15 & 15\end{array}\right]$} & {$\left[\begin{array}{ll}15 & 15\end{array}\right]$} & {$\left[\begin{array}{ll}14 & 15\end{array}\right]$} & {$\left[\begin{array}{ll}14 & 15\end{array}\right]$} \\
\hline Aix 3 & 7 & 7 & 7 & 7 & 7 & {$\left[\begin{array}{ll}6 & 7\end{array}\right]$} & {$\left[\begin{array}{ll}5 & 8\end{array}\right]$} & {$\left[\begin{array}{ll}5 & 8\end{array}\right]$} & [6 6 6] & {$\left[\begin{array}{ll}5 & 8\end{array}\right]$} \\
\hline Avignon & 31 & 31 & 31 & 31 & 31 & 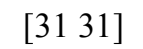 & 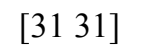 & {$\left[\begin{array}{ll}31 & 31\end{array}\right]$} & {$\left[\begin{array}{ll}30 & 31\end{array}\right]$} & {$\left[\begin{array}{ll}30 & 31\end{array}\right]$} \\
\hline Bourdeaux1 & 16 & 16 & 16 & 17 & 17 & {$\left[\begin{array}{ll}16 & 18\end{array}\right]$} & {$\left[\begin{array}{ll}16 & 18\end{array}\right]$} & {$\left[\begin{array}{ll}16 & 18\end{array}\right]$} & {$\left[\begin{array}{ll}16 & 18\end{array}\right]$} & {$\left[\begin{array}{ll}16 & 18\end{array}\right]$} \\
\hline Bourdeaux2 & 13 & 13 & 13 & 13 & 13 & {$\left[\begin{array}{ll}12 & 14\end{array}\right]$} & {$\left[\begin{array}{ll}12 & 14\end{array}\right]$} & {$\left[\begin{array}{ll}10 & 14\end{array}\right]$} & {$\left[\begin{array}{ll}10 & 14\end{array}\right]$} & {$\left[\begin{array}{ll}10 & 15\end{array}\right]$} \\
\hline Bourdeaux3 & 25 & 25 & 25 & 24 & 24 & {$\left[\begin{array}{ll}23 & 25\end{array}\right]$} & {$\left[\begin{array}{ll}23 & 25\end{array}\right]$} & {$\left[\begin{array}{ll}23 & 25\end{array}\right]$} & {$\left[\begin{array}{ll}23 & 25\end{array}\right]$} & {$\left[\begin{array}{ll}23 & 25\end{array}\right]$} \\
\hline Bourdeaux4 & 23 & 23 & 23 & 23 & 23 & {$\left[\begin{array}{ll}23 & 24\end{array}\right]$} & {$\left[\begin{array}{ll}23 & 25\end{array}\right]$} & {$\left[\begin{array}{ll}23 & 25\end{array}\right]$} & {$\left[\begin{array}{ll}23 & 25\end{array}\right]$} & {$\left[\begin{array}{ll}23 & 25\end{array}\right]$} \\
\hline $\mathrm{Pau}$ & 26 & 26 & 26 & 26 & 26 & {$\left[\begin{array}{ll}26 & 26\end{array}\right]$} & {$\left[\begin{array}{ll}26 & 26\end{array}\right]$} & {$\left[\begin{array}{ll}26 & 27\end{array}\right]$} & {$\left[\begin{array}{ll}26 & 27\end{array}\right]$} & {$\left[\begin{array}{ll}26 & 27\end{array}\right]$} \\
\hline Grenoble1 & 19 & 19 & 19 & 19 & 19 & [19 19] & {$\left[\begin{array}{ll}18 & 19\end{array}\right]$} & {$\left[\begin{array}{ll}18 & 19\end{array}\right]$} & {$\left[\begin{array}{ll}18 & 20\end{array}\right]$} & {$\left[\begin{array}{ll}17 & 20\end{array}\right]$} \\
\hline Grenoble2 & 17 & 17 & 17 & 17 & 17 & {$\left[\begin{array}{ll}16 & 18\end{array}\right]$} & {$\left[\begin{array}{ll}16 & 18\end{array}\right]$} & {$\left[\begin{array}{ll}16 & 19\end{array}\right]$} & {$\left[\begin{array}{ll}16 & 19\end{array}\right]$} & {$\left[\begin{array}{ll}16 & 19\end{array}\right]$} \\
\hline Grenoble3 & 8 & 9 & 9 & 8 & 8 & {$\left[\begin{array}{ll}8 & 11\end{array}\right]$} & {$\left[\begin{array}{ll}8 & 12\end{array}\right]$} & {$\left[\begin{array}{ll}7 & 12\end{array}\right]$} & {$\left[\begin{array}{ll}7 & 13\end{array}\right]$} & {$\left[\begin{array}{ll}6 & 13\end{array}\right]$} \\
\hline Lille1 & 12 & 11 & 12 & 11 & 11 & {$\left[\begin{array}{ll}10 & 13\end{array}\right]$} & {$\left[\begin{array}{ll}9 & 12\end{array}\right]$} & {$\left[\begin{array}{ll}9 & 13\end{array}\right]$} & {$\left[\begin{array}{ll}8 & 13\end{array}\right]$} & {$\left[\begin{array}{ll}7 & 13\end{array}\right]$} \\
\hline Lille2 & 28 & 28 & 28 & 28 & 28 & {$\left[\begin{array}{ll}28 & 28\end{array}\right]$} & {$\left[\begin{array}{ll}27 & 28\end{array}\right]$} & {$\left[\begin{array}{ll}27 & 29\end{array}\right]$} & [27 29] & [27 29] \\
\hline Lille3 & 32 & 32 & 32 & 32 & 32 & {$\left[\begin{array}{ll}32 & 33\end{array}\right]$} & {$\left[\begin{array}{ll}32 & 33\end{array}\right]$} & {$\left[\begin{array}{ll}32 & 33\end{array}\right]$} & {$\left[\begin{array}{ll}32 & 33\end{array}\right]$} & {$\left[\begin{array}{ll}32 & 33\end{array}\right]$} \\
\hline Lyon 1 & 20 & 20 & 20 & 20 & 20 & {$\left[\begin{array}{ll}20 & 20\end{array}\right]$} & {$\left[\begin{array}{ll}20 & 20\end{array}\right]$} & {$\left[\begin{array}{ll}20 & 20\end{array}\right]$} & {$\left[\begin{array}{ll}20 & 20\end{array}\right]$} & {$\left[\begin{array}{ll}20 & 21\end{array}\right]$} \\
\hline Lyon2 & 18 & 18 & 17 & 18 & 18 & {$\left[\begin{array}{ll}16 & 18\end{array}\right]$} & {$\left[\begin{array}{ll}16 & 19\end{array}\right]$} & {$\left[\begin{array}{ll}16 & 19\end{array}\right]$} & [1619] & {$\left[\begin{array}{ll}16 & 19\end{array}\right]$} \\
\hline Lyon3 & 14 & 14 & 14 & 14 & 13 & {$\left[\begin{array}{ll}13 & 14\end{array}\right]$} & {$\left[\begin{array}{ll}13 & 14\end{array}\right]$} & {$\left[\begin{array}{ll}13 & 14\end{array}\right]$} & {$\left[\begin{array}{ll}12 & 14\end{array}\right]$} & {$\left[\begin{array}{ll}12 & 15\end{array}\right]$} \\
\hline Montpellier1 & 4 & 4 & 4 & 4 & 4 & [4 4] & {$\left[\begin{array}{ll}3 & 5\end{array}\right]$} & {$\left[\begin{array}{ll}3 & 5\end{array}\right]$} & {$\left[\begin{array}{ll}3 & 5\end{array}\right]$} & {$\left[\begin{array}{ll}3 & 8\end{array}\right]$} \\
\hline Montpellier2 & 21 & 21 & 21 & 21 & 21 & {$\left[\begin{array}{ll}21 & 21\end{array}\right]$} & {$\left[\begin{array}{ll}21 & 21\end{array}\right]$} & {$\left[\begin{array}{ll}21 & 21\end{array}\right]$} & {$\left[\begin{array}{ll}20 & 21\end{array}\right]$} & {$\left[\begin{array}{ll}20 & 21\end{array}\right]$} \\
\hline Montpellier3 & 9 & 9 & 9 & 9 & 9 & [ $\left.\begin{array}{ll}7 & 12\end{array}\right]$ & {$\left[\begin{array}{ll}7 & 12\end{array}\right]$} & {$\left[\begin{array}{ll}7 & 12\end{array}\right]$} & {$\left[\begin{array}{ll}6 & 12\end{array}\right]$} & {$\left[\begin{array}{ll}6 & 13\end{array}\right]$} \\
\hline Metz & 29 & 29 & 29 & 29 & 29 & {$\left[\begin{array}{ll}29 & 30\end{array}\right]$} & {$\left[\begin{array}{ll}28 & 30\end{array}\right]$} & {$\left[\begin{array}{ll}27 & 30\end{array}\right]$} & {$\left[\begin{array}{ll}27 & 30\end{array}\right]$} & {$\left[\begin{array}{ll}27 & 30\end{array}\right]$} \\
\hline Nancyl & 33 & 33 & 33 & 33 & 33 & {$\left[\begin{array}{ll}32 & 33\end{array}\right]$} & {$\left[\begin{array}{ll}32 & 33\end{array}\right]$} & {$\left[\begin{array}{ll}32 & 33\end{array}\right]$} & {$\left[\begin{array}{ll}32 & 33\end{array}\right]$} & {$\left[\begin{array}{ll}32 & 33\end{array}\right]$} \\
\hline Nancy2 & 24 & 24 & 24 & 24 & 24 & {$\left[\begin{array}{ll}24 & 25\end{array}\right]$} & {$\left[\begin{array}{ll}23 & 25\end{array}\right]$} & {$\left[\begin{array}{ll}23 & 25\end{array}\right]$} & {$\left[\begin{array}{ll}23 & 25\end{array}\right]$} & {$\left[\begin{array}{ll}23 & 25\end{array}\right]$} \\
\hline Paris1 & 2 & 2 & 2 & 2 & 2 & [2 2] & {$\left[\begin{array}{ll}2 & 2\end{array}\right]$} & {$\left[\begin{array}{ll}2 & 2\end{array}\right]$} & [2 2] & [2 2] \\
\hline Paris8 & 1 & 1 & 1 & 1 & 1 & {$\left[\begin{array}{ll}1 & 1\end{array}\right]$} & {$\left[\begin{array}{ll}1 & 1\end{array}\right]$} & {$\left[\begin{array}{ll}1 & 1\end{array}\right]$} & {$\left[\begin{array}{ll}1 & 1\end{array}\right]$} & {$\left[\begin{array}{ll}1 & 1\end{array}\right]$} \\
\hline Paris11 & 5 & 5 & 5 & 5 & 6 & {$\left[\begin{array}{ll}5 & 8\end{array}\right]$} & [4 9] & {$\left[\begin{array}{ll}4 & 10\end{array}\right]$} & {$\left[\begin{array}{ll}4 & 10\end{array}\right]$} & {$\left[\begin{array}{ll}5 & 10\end{array}\right]$} \\
\hline Paris13 & 10 & 9 & 9 & 10 & 9 & {$\left[\begin{array}{ll}6 & 10\end{array}\right]$} & {$\left[\begin{array}{ll}5 & 11\end{array}\right]$} & {$\left[\begin{array}{ll}5 & 11\end{array}\right]$} & {$\left[\begin{array}{ll}5 & 12\end{array}\right]$} & {$\left[\begin{array}{ll}4 & 12\end{array}\right]$} \\
\hline Strasbourg & 3 & 3 & 3 & 3 & 3 & {$\left[\begin{array}{ll}3 & 3\end{array}\right]$} & {$\left[\begin{array}{ll}3 & 4\end{array}\right]$} & {$\left[\begin{array}{ll}3 & 4\end{array}\right]$} & [3 4] & {$\left[\begin{array}{ll}3 & 4\end{array}\right]$} \\
\hline Toulouse1 & 11 & 11 & 11 & 11 & 11 & {$\left[\begin{array}{ll}9 & 12\end{array}\right]$} & {$\left[\begin{array}{ll}9 & 13\end{array}\right]$} & {$\left[\begin{array}{ll}8 & 13\end{array}\right]$} & {$\left[\begin{array}{ll}8 & 13\end{array}\right]$} & {$\left[\begin{array}{ll}8 & 14\end{array}\right]$} \\
\hline Toulouse2 & 22 & 22 & 22 & 22 & 22 & {$\left[\begin{array}{ll}22 & 22\end{array}\right]$} & {$\left[\begin{array}{ll}22 & 22\end{array}\right]$} & {$\left[\begin{array}{ll}22 & 22\end{array}\right]$} & {$\left[\begin{array}{ll}22 & 22\end{array}\right]$} & {$\left[\begin{array}{ll}22 & 22\end{array}\right]$} \\
\hline Toulouse3 & 27 & 27 & 27 & 27 & 27 & {$\left[\begin{array}{ll}27 & 27\end{array}\right]$} & [27 29] & {$\left[\begin{array}{ll}26 & 29\end{array}\right]$} & {$\left[\begin{array}{ll}26 & 29\end{array}\right]$} & {$\left[\begin{array}{ll}26 & 29\end{array}\right]$} \\
\hline Versailles & 30 & 30 & 30 & 30 & 30 & {$\left[\begin{array}{ll}29 & 30\end{array}\right]$} & {$\left[\begin{array}{ll}29 & 30\end{array}\right]$} & {$\left[\begin{array}{ll}29 & 30\end{array}\right]$} & {$\left[\begin{array}{ll}29 & 31\end{array}\right]$} & {$\left[\begin{array}{ll}28 & 31\end{array}\right]$} \\
\hline
\end{tabular}

Table 10. Robust ranking for evaluating the Academic Profile performance of the excellence German universities using different values of the perturbation $\mathrm{s}$.

\begin{tabular}{|c|c|c|c|c|c|c|c|c|c|c|}
\hline & \multicolumn{5}{|c|}{ Median Rank } & \multicolumn{5}{|c|}{ [5th quantile, 95 th quantile] } \\
\hline & $\mathrm{s}=0.10 \mathrm{w}_{\mathrm{j}}$ & $\mathrm{s}=0.15 \mathrm{w}_{\mathrm{j}}$ & $\mathrm{s}=0.20 \mathrm{w}_{\mathrm{j}}$ & $\mathrm{s}=0.25 \mathrm{w}_{\mathrm{j}}$ & $\mathrm{s}=0.30 \mathrm{w}_{\mathrm{j}}$ & $\mathrm{s}=0.10 \mathrm{w}_{\mathrm{j}}$ & $\mathrm{s}=0.15 \mathrm{w}_{\mathrm{j}}$ & $\mathrm{s}=0.20 \mathrm{w}_{\mathrm{j}}$ & $\mathrm{s}=0.25 \mathrm{w}_{\mathrm{j}}$ & $\mathrm{s}=0.30 \mathrm{w}_{\mathrm{j}}$ \\
\hline Constance & 6 & 6 & 6 & 6 & 6 & {$\left[\begin{array}{ll}5 & 6\end{array}\right]$} & {$\left[\begin{array}{ll}5 & 6\end{array}\right]$} & {$\left[\begin{array}{ll}5 & 6\end{array}\right]$} & {$\left[\begin{array}{ll}5 & 6\end{array}\right]$} & {$\left[\begin{array}{ll}5 & 6\end{array}\right]$} \\
\hline Freiburg & 8 & 8 & 8 & 8 & 8 & {$\left[\begin{array}{ll}8 & 8\end{array}\right]$} & [8 9] & [8 9] & [8 8 8 $]$ & [8 8 9 $]$ \\
\hline Fu Berlin & 2 & 2 & 2 & 2 & 2 & {$\left[\begin{array}{ll}2 & 2\end{array}\right]$} & [ll 3 3] & {$\left[\begin{array}{ll}2 & 3\end{array}\right]$} & {$\left[\begin{array}{ll}2 & 3\end{array}\right]$} & {$\left[\begin{array}{ll}2 & 3\end{array}\right]$} \\
\hline Göttingen & 3 & 3 & 3 & 3 & 3 & {$\left[\begin{array}{ll}3 & 4\end{array}\right]$} & [2 4] & {$\left[\begin{array}{ll}2 & 4\end{array}\right]$} & {$\left[\begin{array}{ll}2 & 4\end{array}\right]$} & {$\left[\begin{array}{ll}2 & 4\end{array}\right]$} \\
\hline Heidelberg & 1 & 1 & 1 & 1 & 1 & {$\left[\begin{array}{ll}1 & 1\end{array}\right]$} & {$\left[\begin{array}{ll}1 & 1\end{array}\right]$} & {$\left[\begin{array}{ll}1 & 1\end{array}\right]$} & {$\left[\begin{array}{ll}1 & 1\end{array}\right]$} & {$\left[\begin{array}{ll}1 & 1\end{array}\right]$} \\
\hline Karlsruhe & 9 & 9 & 9 & 9 & 9 & {$\left[\begin{array}{ll}9 & 9\end{array}\right]$} & [8 9] & {$\left[\begin{array}{ll}8 & 9\end{array}\right]$} & {$\left[\begin{array}{ll}8 & 9\end{array}\right]$} & {$\left[\begin{array}{ll}8 & 9\end{array}\right]$} \\
\hline LMUMunich & 7 & 7 & 7 & 7 & 7 & [7 7] & [7 7] & {$\left[\begin{array}{ll}7 & 7\end{array}\right]$} & {$\left[\begin{array}{ll}7 & 7\end{array}\right]$} & {$\left[\begin{array}{ll}7 & 7\end{array}\right]$} \\
\hline RWTHAachen & 5 & 5 & 5 & 5 & 5 & {$\left[\begin{array}{ll}5 & 6\end{array}\right]$} & {$\left[\begin{array}{ll}5 & 6\end{array}\right]$} & {$\left[\begin{array}{ll}5 & 6\end{array}\right]$} & {$\left[\begin{array}{ll}5 & 6\end{array}\right]$} & {$\left[\begin{array}{ll}5 & 6\end{array}\right]$} \\
\hline TUMunich & 4 & 4 & 4 & 4 & 4 & [3 4] & [3 4 ] & [3 4] & {$\left[\begin{array}{ll}3 & 4\end{array}\right]$} & [2 4] \\
\hline
\end{tabular}




\section{References}

[1] Aguillo, I., Bar-Ilan, J., Levene, M. and Ortega, J.L. (2010). Comparing university rankings. Scientometrics, 85, pp-243-256.

[2] Bastedo, M. and Bowman, N. (2010) College Rankings as an Interorganizational Dependency: Establishing the Foundation for Strategic and Institutional Accounts. Research in Higher Education (doi: 10.1007/s11162-010-9185-0)

[3] CENTRE FOR HIGHER EDUCATION DEVELOPMENT (CHE), UNESCO EUROPEAN CENTRE FOR HIGHER EDUCATION (CEPES), INSTITUTE FOR HIGHER EDUCATION POLICY (IHEP), 2006, Berlin principles on ranking of higher education institutions, Berlin. Available online at: http://www.che.de/downloads/Berlin/Principles/IREG/TEXTsymbol/534.pdf

[4] Chen, Y. and Liu, N.C. (2008) Examining Major Rankings According to the Berlin Principles. Higher Education in Europe, 33, pp. 201-208.

[5] Cook, J.M (1958) Rational formulae for the production of a spherically symmetric probability distribution. Math. Tables Other Aids Comp., 11, pp. 81-82

[6] Debreu, G. (1960) Topological methods in cardinal utility theory. In: K.J. Arrow, S. Karlin and P. Suppes, Editors, Mathematical methods in the social sciences, Stanford University Press, pp. 16-26.

[7] Dill, D. and Soo, M. (2004) Is there a global definition of academic quality? A cross-national analysis of university ranking system. Public Policy for Academic Quality (Chapel Hill, NC, University of North Carolina).

[8] Ding, J. and Qiu, J. (2011) An approach to improve the indicator weights of scientific and technological competitiveness evaluation of Chinese universities. Scientometrics, 86, pp.285-297 (doi: 10.1007/s11192-010-0268-7).

[9] Federkail, G. (2008) Rankings and Quality Assurance in Higher Education. Higher Education in Europe, 33, 219-231.

[10] Geraci, M. and Degli, M. (2011) Where do Italian universities stand? An in-depth statistical analysis of national and international rankings. Scientometrics (doi: 10.1007/s11192-011-0350-9).

[11] Harvey , L. , Editor (2008) Rankings of Higher Education Institutions: A Critical Review, Quality in Higher Education, 14 : 3, pp.187- 207.

[12] Marsaglia, G. (1972) Choosing a point from the surface of a sphere. The Annals of Mathematical Statistics, 43, pp.645-646.

[13] Sadlak, J., Merisotis, J. and Liu, N.C. (2008) University Rankings: Seeking Prestige, Raising Visibility and Embedding Quality -- the Editors' Views. Higher Education in Europe, 33, pp. 195-199. 
[14] Saisana, M., Saltelli, A. and Tarantola, S. (2005) Uncertainty and sensitivity analysis techniques as tools for the quality assessment of composite indicators. Journal of the Royal Statistical Association A, 168, pp.307-323.

[15] Saisana M., D'Hombres B. (2008) Higher Education Rankings: Robustness and Critical Assessment. JRC Scientific and Technical Reports, European Commission.

[16] Stolz, I., Hendel, D. and Horn, A. (2010) Ranking of rankings: benchmarking twenty-five higher education ranking systems in Europe. Higher Education, 60, pp507-528.

[17] Pike, G.R. (2004) Measuring quality: A comparison of U.S. News Rankings and NSSE Benchmarks. Research in Higher Education, 45 : 2, pp. 193-208.

[18] Usher, A. and Savino, M. (2007) A global survey of university ranking and league tables. Higher Education in Europe, 32 : 1, pp.5-15. 